\title{
Sexual Dysfunction in Men with Type 2 Diabetes Mellitus: Prevalence and Severity-An Observational Study
}

\author{
Ratan Halder ${ }^{1}$, Kalimujjaman Molla ${ }^{2}$, Partha Pratim Chakraborty ${ }^{3}$, Surojit Das ${ }^{4}$, Abhishek P Gupta ${ }^{5}$, Kripasindhu Gantait ${ }^{6}$
}

\begin{abstract}
Background: Individuals suffering from diabetes mellitus are at higher risk of all forms of sexual dysfunctions, but there is hardly any study in India that discussed all aspects of sexual activity in diabetic patients. Hence, the current study was conducted to estimate the prevalence of the sexual disorder in diabetic patients.

Materials and methods: One hundred nine diabetic men were selected, who fulfilled the inclusion criteria and assessed by the International Index of Erectile Function-5 (IIEF-5) questionnaire.

Result: The prevalence of erectile dysfunction (ED) was $89.9 \%$, out of which $58.16 \%$ reported spontaneously with maximum (62.4\%) having severe $E D$, andthe IIEF- 5 score provided by patients themself and their spouses was statistically significant ( $p$-value $=0.000$ ). The hypoactive sexual desire and decreased libido were $25.7 \%$ and $42.2 \%$, respectively. A total of $68.8 \%$ of participants failed to attain orgasm, $56.9 \%$ of participants had premature ejaculation but $20.2 \%$ had delayed ejaculation, and $61.47 \%$ had all three of erection, ejaculation, and orgasm problems.

Conclusion: This study concluded that nine out of ten diabetic men were suffering from ED and only interviewing the male sexual partner is sufficient for the evaluation of ED and also concluded that ED is not so much social stigma nowadays. Other sexual dysfunction should be addressed for better sexual satisfaction outcomes.

Keywords: Diabetes mellitus, International Index of Erectile Function-5, Prevalence, Sexual dysfunction.

Bengal Physician Journal (2021): 10.5005/jp-journals-10070-7053
\end{abstract}

\section{INTRODUCTION}

Sexuality is an important aspect of health, which can impact the overall well-being of men and women. The sexual activity comprises desire, arousal, erection, ejaculation, and orgasm. Disorders of sexual functioning are common among men and women of all ages, ethnicities, and cultural backgrounds. Individuals suffering from diabetes mellitus (DM) are at higher risk of all forms of sexual dysfunctions. ${ }^{1}$ Around 463 million people are suffering from DM globally and 77 million people in India (International Diabetes Federation 2019). ${ }^{2}$ Among the diabetic population, the prevalence of erectile dysfunction (ED) ranges from 35 to $90 \%{ }^{3}$ and Amitava et al. ${ }^{4}$ in their study conducted in eastern India and reported the prevalence of $38.95 \%$. There is hardly any study in India that discussed other aspects of sexual activity in diabetic patients. Though sexual activity is considered, to be one of the important indicators of quality of life but in developing countries like India, it is often neither discussed by the patients nor addressed by the physician because of lack of knowledge, awareness, and sociocultural taboos.

\section{Aims and Objectives}

The aim of this study is to assess the overall prevalence of sexual dysfunction (dysfunction of desire, arousal, erection, ejaculation, and orgasm) in patients with diabetes. The objective of this study is to investigate the relationship between the duration of DM and prevalence of sexual dysfunction.

\section{Specific Objectives}

- To find out the prevalence of self-reported ED and ED diagnosed with the questionnaire.

- To find out the prevalence of different severity of ED.
1-3,5,6 Department of Medicine, Midnapore Medical College, Paschim Medinipur, West Bengal, India

${ }^{4}$ Department of Radiology, Midnapore Medical College, Paschim Medinipur, West Bengal, India

Corresponding Author: Kripasindhu Gantait, Department of Medicine, Midnapore Medical College, Paschim Medinipur, West Bengal, India, e-mail: drkripa2000@gmail.com

How to cite this article: Halder R, Molla K, Chakraborty PP, et al. Sexual Dysfunction in Men with Type 2 Diabetes Mellitus: Prevalence and Severity-An Observational Study. Bengal Physician Journal 2021;8(2):34-37.

Source of support: Nil

Conflict of interest: None

- To find out the correlation between the severity of ED obtained from patients and their spouses.

- To find out the relationship between the severity of ED and duration of diabetes.

\section{Materials and Methods}

This is a single-centered, hospital-based, cross-sectional study that has been conducted in the Department of General Medicine in the Midnapore Medical College and Hospital, West Bengal, for a period of 1 year after taking approval of the Institutional Ethics Committee. One hundred nine type 2 diabetic men were selected who were married and aged between 18 and 65 years irrespective of the duration of disease and the willingness to participate in this study. We excluded the patients who have chronic kidney disease (Stage 3-5), chronic liver disease, history of spinal injury,

(c) The Author(s). 2021 Open Access This article is distributed under the terms of the Creative Commons Attribution 4.0 International License (https:// creativecommons.org/licenses/by-nc/4.0/), which permits unrestricted use, distribution, and non-commercial reproduction in any medium, provided you give appropriate credit to the original author(s) and the source, provide a link to the Creative Commons license, and indicate if changes were made. The Creative Commons Public Domain Dedication waiver (http://creativecommons.org/publicdomain/zero/1.0/) applies to the data made available in this article, unless otherwise stated. 
surgery or trauma to pelvic girdle, sexually transmitted diseases, malignancy, acquired immunodeficiency syndrome, tuberculosis, chronic obstructive pulmonary diseases, and congestive heart failure. The International Index of Erectile Function-5 (IIEF-5) is a well-validated questionnaire (Table 1), which was used for the evaluation of sexual dysfunction and to assess the severity of ED (total score 1-7 = severe, $8-11=$ moderate, $12-16=$ mild - moderate, 17-21 = mild, $22-25=$ no ED). A detailed history had been taken and the physical examination was done using a data sheet. We performed biochemical studies including fasting and postprandial plasma glucose level, glycosylated hemoglobin, serum creatinine, and liver function tests.

\section{Data Analysis}

For statistical analysis, data were entered in a Microsoft spreadsheet and then analyzed by IBM SPSS Statistics version 2.0 software. Data have been summarized as mean and standard deviation (SD) for numerical variables and percentage for categorical variables. A bivariate Pearson correlation test has been done. A $p$ value of $<0.05$ has been considered statistically significant.

\section{Result}

We conducted this study in the department of general medicine in our hospital. One hundred nine patients were selected for this study. The mean age of our study population was $46.8( \pm 8.8)$ and we found that most of the study population (52.2\%) is from 56-60 years of age followed by $40.4 \%$ from 30 to 45 years of age. In our study population, $52.3 \%$ were overweight and $45.87 \%$ had a waist circumference $\geq 90 \mathrm{~cm}$. Among the 109 patients, at the time of the interview, 82 provided recent $\mathrm{HbA} 1 \mathrm{c}$, among them $43.9 \%$ had excellent diabetes control and $35.4 \%$ had poor diabetes control. Glycemic status was not significantly correlated with the diagnosis of erectile function ( $p$-value $=0.099$ ). In our study population, $71.56 \%$ was on oral antidiabetic drug and $28.44 \%$ was on injection insulin or combined medication (Table 2).

We found that $89.9 \%$ had ED, out of which $58.16 \%$ reported spontaneously and the rest of them diagnosed by questionnaire. We noticed that $62.4 \%$ had severe ED as per the IIEF-5 score provided by participants and $49.5 \%$ had severe ED according to their spouses. We found that the IIEF- 5 score provided by patients themself and their spouses was statistically significant ( $p$-value $=0.000$ ) (Table 3 ).

Among the 109 participants, we noticed that $25.7 \%$ of participants had a hypoactive sexual desire and $74.5 \%$ had a normal desire for the sexual act. In our study population, $42.2 \%$ had decreased libido but $10.1 \%$ had no arousal at all. We also noticed that $68.8 \%$ of participants failed to attain orgasm. We also found that $56.9 \%$ of participants had premature ejaculation, $22.9 \%$ had normal ejaculation but $20.2 \%$ had delayed ejaculation, and $66.97 \%$ had both orgasm and ejaculation problems where as $61.47 \%$ had all three of erection, ejaculation, and orgasm problems (Table 4).

The mean duration of diabetes in our study population was $5.83( \pm 5.79)$ years with 55.96 and $19.27 \%$ of participants having less than 5 years and more than 10 years of duration of diabetes, respectively. Longer duration of diabetes was significantly associated with increased incidence and severity of ED ( $p$-value $=0.003$ ), along with increased incidence of decreased sexual desire ( $p$-value $=0.001)$, ejaculation dysfunction ( $p$-value $=0.005)$, and absence of orgasm ( $p$-value $=0.006)$ but was not statistically significant $(p$-value $=0.134$ ) in sexual arousal dysfunction (Table 5).

\section{Discussion}

In our study, we recruited 109 married type 2 diabetic men between age 18 and 65 years and conducted over 12 months. Amitava et al. ${ }^{4}$ conducted a study in eastern India with 113 male diabetic patients and Zeeshan et al. ${ }^{5}$ in northern India with 184 male diabetic patients.

The present study comprised of $52.2 \%$ of participants in the age-group of $46-60$ years, $40.4 \%$ of $30-45$ years, $2.8 \%$ of less than 30 years, and $4.6 \%$ in the age above 60 years. The mean age of the study population was $46.8( \pm 8.8)$ years, which was lower than that of the study conducted by De beradis et al. ${ }^{6}$ and Siu et al. ${ }^{7}$ where it was $62( \pm 10)$ years and $58.3( \pm 10.4)$ years, respectively, but higher than the study conducted by Amitava et al. ${ }^{4}$ where it was 42.7 years. The minimum age in the study group was 21 years

Table 1: IIEF-5-validated questionnaire

\begin{tabular}{|c|c|c|c|c|c|c|}
\hline \multicolumn{7}{|c|}{ Over the past 6 months } \\
\hline 1 & $\begin{array}{l}\text { How do you rate your } \\
\text { confidence that you could get } \\
\text { and keep an erection? }\end{array}$ & $\begin{array}{l}\text { Very low } \\
1\end{array}$ & $\begin{array}{l}\text { Low } \\
2\end{array}$ & $\begin{array}{l}\text { Moderate } \\
3\end{array}$ & $\begin{array}{l}\text { High } \\
4\end{array}$ & $\begin{array}{l}\text { Very high } \\
5\end{array}$ \\
\hline 2 & $\begin{array}{l}\text { When you had erections with sexual } \\
\text { stimulation, how often were your } \\
\text { erections hard enough for } \\
\text { penetration? }\end{array}$ & $\begin{array}{l}\text { Almost never/ } \\
\text { never } \\
1\end{array}$ & $\begin{array}{l}\text { A few times } \\
\text { (much less than } \\
\text { half the time) } \\
2\end{array}$ & $\begin{array}{l}\text { Sometimes } \\
\text { (about half } \\
\text { the time) } \\
3\end{array}$ & $\begin{array}{l}\text { Most times } \\
\text { (much more than } \\
\text { half the time) } \\
4\end{array}$ & $\begin{array}{l}\text { Almost } \\
\text { always/always } \\
5\end{array}$ \\
\hline 3 & $\begin{array}{l}\text { During sexual intercourse, how often } \\
\text { were you able to maintain your } \\
\text { erection after you had } \\
\text { penetrated (entered) your partner? }\end{array}$ & $\begin{array}{l}\text { Almost never/ } \\
\text { never } \\
1\end{array}$ & $\begin{array}{l}\text { A few times } \\
\text { (much less than } \\
\text { half the time) } \\
2\end{array}$ & $\begin{array}{l}\text { Sometimes } \\
\text { (about half } \\
\text { the time) } \\
3\end{array}$ & $\begin{array}{l}\text { Most times } \\
\text { (much more than } \\
\text { half the time) } \\
4\end{array}$ & $\begin{array}{l}\text { Almost } \\
\text { always/always } \\
5\end{array}$ \\
\hline 4 & $\begin{array}{l}\text { During sexual intercourse, how } \\
\text { difficult was it to maintain your } \\
\text { erection to completion of intercourse? }\end{array}$ & $\begin{array}{l}\text { Extremely } \\
\text { difficult } \\
1\end{array}$ & $\begin{array}{l}\text { Very difficult } \\
2\end{array}$ & $\begin{array}{l}\text { Difficult } \\
3\end{array}$ & $\begin{array}{l}\text { Slight difficult } \\
4\end{array}$ & $\begin{array}{l}\text { Not difficult } \\
5\end{array}$ \\
\hline 5 & $\begin{array}{l}\text { When you attempted sexual } \\
\text { intercourse, how often was it } \\
\text { satisfactory for you? }\end{array}$ & $\begin{array}{l}\text { Almost never/ } \\
\text { never } \\
1\end{array}$ & $\begin{array}{l}\text { A few times } \\
\text { (much less than } \\
\text { half the time) } \\
2\end{array}$ & $\begin{array}{l}\text { Sometimes } \\
\text { (about half } \\
\text { the time) } \\
3\end{array}$ & $\begin{array}{l}\text { Most times } \\
\text { (much more than } \\
\text { half the time) } \\
4\end{array}$ & $\begin{array}{l}\text { Almost } \\
\text { always/always } \\
5\end{array}$ \\
\hline
\end{tabular}

The IIEF- 5 score is the sum of the ordinal responses to the five items; thus, the score can range from 5 to 25 
Table 2: Distribution of the study population according to basic information

\begin{tabular}{lcc}
\hline Variables & $N=109(\%)$ & Mean $(S D)$ \\
\hline Age at diagnosis & & $46.8( \pm 8.8)$ \\
Age-group & & \\
$<30$ & $3(2.8)$ & \\
$30-45$ & $44(40.4)$ & \\
$46-60$ & $57(52.2)$ & \\
$>60$ & $5(4.6)$ & \\
BMI (109) & $49(45)$ \\
Normal & $57(52.3)$ \\
Overweight & $3(2.8)$ \\
Obese & & \\
Waist circumference (109) & $59(54.13)$ \\
$<90 \mathrm{~cm}$ & $50(45.87)$ \\
$\geq 90 \mathrm{~cm}$ & \\
HbA1C (82) & $36(43.9)$ \\
Excellent $(<7)$ & $29(35.4)$ \\
Good (7-8) & $17(20.7)$ \\
Poor (>8) & \\
Type of treatment for diabetes & $78(71.56)$ \\
Oral antidiabetic & $31(28.44)$ \\
Insulin/combined &
\end{tabular}

Table 3: Distribution of study population according to erectile dysfunction and severity

\begin{tabular}{lc}
\hline Variables & $N=109(\%)$ \\
\hline Erectile dysfunction & $98(89.9)$ \\
Severity of ED (98) & \\
Mild & $8(7.3)$ \\
Mild-moderate & $7(6.4)$ \\
Moderate & $15(13.8)$ \\
Severe & $68(62.4)$ \\
Mode of diagnosis of ED (98) & \\
Spontaneous reporting & $57(58.16)$ \\
By questionnaire & $41(41.84)$ \\
Severity of ED (spouse) (95) & \\
Mild & $4(3.7)$ \\
Mild-moderate & $7(6.4)$ \\
Moderate & $30(27.5)$ \\
Severe & $54(49.5)$ \\
\hline
\end{tabular}

Table 4: Distribution of the study population according to other components of sexual dysfunction

\begin{tabular}{ll}
\hline Variables & $N=109(\%)$ \\
\hline Desire & \\
Normal & $81(74.3)$ \\
Decrease & $28(25.7)$ \\
Arousal & \\
Present & $52(47.7)$ \\
Decreased & $46(42.2)$ \\
Absent & $11(10.1)$ \\
Orgasm & \\
Yes & $34(31.2)$ \\
No & $75(68.8)$ \\
Ejaculation & \\
Early & $62(56.9)$ \\
Normal & $25(22.9)$ \\
Delayed & $22(20.2)$ \\
\hline
\end{tabular}

Table 5: Distribution of the study population as per the duration of diabetes in years

\begin{tabular}{lcc}
\hline Variables & $N=109(\%)$ & Mean $(S D)$ \\
\hline Duration of diabetes (years) & & $5.83( \pm 5.79)$ \\
$<5$ & $61(55.96)$ & \\
$5-10$ & $27(24.77)$ & \\
$>10$ & $21(19.27)$ & \\
\hline
\end{tabular}

and maximum age of 65 years was noted, giving an age range of 44 years. The age of the participants was not normally distributed.

We obtained the prevalence of ED $89.9 \%$ comprising $62.4 \%$ severe ED. Sasaki et al. ${ }^{8}$ reported that the prevalence of ED in the type 2 diabetic population was $90 \%$. Amitava et al. ${ }^{4}$ reported the prevalence of $38.95 \%$ and Zeeshan et al. ${ }^{5}$ reported the prevalence of severe ED $56.5 \%$, which is lower than that of our result. Siu et al. ${ }^{7}$ reported that the prevalence of ED in diabetic patients was $63.6 \%$ among Chinese. The higher prevalence of ED in our study is probably due to the small sample size. Among the participants having ED, 58.16\% reported their problems spontaneously and $41.84 \%$ of participants were diagnosed by the IIEF- 5 questionnaire.

It had been found that $49.5,27.5,6.4$, and $3.7 \%$ had severe, moderate, mild-moderate, and mild ED, respectively, based on the IIEF-5 score obtained from the spouse of participants. Strong $(r=0.833)$ and significant $(p$-value $=0.000)$ correlation was found between IIEF- 5 score reported by participants and their spouses. So, only interviewing male sexual partner is sufficient for the evaluation and management of ED, in contrast to the guidelines which stated that both partners are needed for the evaluation and management.

It was noticed that $25.7 \%$ of participants had a hypoactive sexual desire and $42.2 \%$ had decreased libido but $10.1 \%$ had no arousal at all. It was also found that $68.8 \%$ of participants failed to attain orgasm and $56.9 \%$ of participants had premature ejaculation but $22.9 \%$ had normal ejaculation while $20.2 \%$ had delayed ejaculation. Rao et al. ${ }^{9}$ reported $2.56 \%$ of hypoactive sexual desire and $8.76 \%$ of premature ejaculation in nondiabetic patients in their study conducted in south India. Pal et al. ${ }^{10}$ reported that $21 \%$ of hypoactive sexual desire and $30 \%$ of premature ejaculation patients attended the special clinic on sexual dysfunction in their study conducted in eastern India. We also noticed that $66.97 \%$ had both orgasm and ejaculation problems whereas $61.47 \%$ had all three of erection, ejaculation, and orgasm problems.

The mean duration of diabetes in our study population was $5.83( \pm 5.79)$ years with a maximum of participants having less than 5 years duration. Longer duration of diabetes was significantly associated with the increased incidence and severity of ED ( $p$-value $=0.003)$. Similar findings were also reported by Zeeshan et al. ${ }^{5}(p$-value $=0.000)$ but Amitava et al. ${ }^{4}$ reported that there was no significant correlation ( $p$-value $=0.610$ ). Longer duration of diabetes was also significantly associated with the increased incidence of decreased sexual desire ( $p$-value $=0.001)$, ejaculation dysfunction ( $p$-value $=0.005)$, and absence of orgasm ( $p$-value $=0.006)$ but was not statistically significant ( $p$-value $=0.134$ ) in sexual arousal dysfunction.

\section{Conclusion}

Sexual intimacy is a basic physiological need. Nine out of ten diabetic men were suffering from ED with maximum having severe ED, which is often ignored. Almost two-thirds of participants reported ED spontaneously, so it is not so much social stigma nowadays. 
It is also noticed that only interviewing the male sexual partner is sufficient for the evaluation of ED as to get the information from female partner is often cumbersome. Other sexual dysfunctions are also prevalent in diabetic men and should be addressed for better sexual satisfaction outcomes. Our study also shows that sexual dysfunction may occur at any stage of type $2 \mathrm{DM}$ and is not related to glycemic control status. Therefore, a large-scale study is required for further evaluation.

\section{ACKnowledgments}

The authors acknowledge the support of the Medical Superintendent of this college, and they are also grateful to the study subjects for their cooperation.

\section{References}

1. Feldman HA, Johannes $C B$, Derby $C A$, et al. Erectile dysfunction and coronary risk factors: prospective results from the Massachusetts male aging study. Prev Med 2000;30(4):328-338. DOI: 10.1006/ pmed.2000.0643.

2. The Global Burden. International Diabetes Federation (IDF). Available online: Diabetes in SEA (idf.org).

3. Malavige LS, Levy JC. Erectile dysfunction in diabetes mellitus. J Sex Med 2009;6(5):1232-1247. DOI:10.1111/j.1743-6109.2008.01168.x.
4. Dan A, Chakraborty K, Mondal M, et al. Erectile dysfunction in patients with diabetes mellitus: its magnitude, predictors and their bio-psycho-social interaction: a study from a developing country.Asian J Psychiatr 2014;7(1):58-65. DOI:10.1016/j.ajp.2013. 10.012 .

5. Anwar Z, Sinha V, MitraS, et al. Erectile dysfunction: an underestimated presentation in patients with diabetes mellitus. Indian J Psychol Med 2017;39(5):600-604. DOI:10.4103/0253-7176.217015.

6. De Berardis G, Franciosi M, Belfiglio M, et al. Erectile dysfunction and quality of life in type 2 diabetic patients: a serious problem too often overlooked. Diabetes Care 2002;25(2):284-291. DOI: 10.2337/ diacare.25.2.284.

7. Siu SC, Lo SK, Wong KW, et al. Prevalence of and risk factors for erectile dysfunction in Hong Kong diabetic patients. Diabet Med 2001;18(9):732-738. DOI: 10.1046/j.0742-3071.2001.00557.x.

8. Sasaki H, Yamasaki H, Ogawa K, et al. Prevalence and risk factors for erectile dysfunction in Japanese diabetics. Diabetes Res Clin Pract 2005;70(1):81-89. DOI:10.1016/j.diabres.2005.02.018.

9. Sathyanarayana Rao TS, Darshan MS, Tandon A. An epidemiological study of sexual disorders in south Indian rural population. Indian J Psychiatry 2015;57(2):150-157. DOI: 10.4103/0019-5545.158143. PMID: 26124520; PMCID: PMC4462783.

10. Pal A, Mallik N, Acharya, R, et al. Epidemiology of patients attending a special clinic on sexual dysfunction from eastern India: a retrospective data review. Med J DY Patil Vidyapeeth 2017;10:542547. DOI: 10.4103/MJDRDYPU.MJDRDYPU_68_17. 